\title{
Neurological long term consequences of deep diving
}

\author{
K Todnem, H Nyland, H Skeidsvoll, R Svihus, P Rinck, B K Kambestad, T Riise, J A Aarli
}

\begin{abstract}
Forty commercial saturation divers, mean age 34.9 (range 24-49) years, were examined one to seven years after their last deep dive (190-500 metres of seawater). Four had by then lost their divers' licence because of neurological problems. Twenty seven ( $68 \%$ ) had been selected by neurological examination and electroencephalography before the deep dives. The control group consisted of 100 men, mean age $34 \cdot 0$ (range 22-48) years. The divers reported significantly more symptoms from the nervous system. Concentration difficulties and paraesthesia in feet and hands were common. They had more abnormal neurological findings by neurological examination compatible with dysfunction in the lumbar spinal cord or roots. They also had a larger proportion of abnormal electroencephalograms than the controls. The neurological symptoms and findings were highly significantly correlated with exposure to deep diving (depth included), but even more significantly correlated to air and saturation diving and prevalence of decompression sickness. Visual evoked potentials, brainstem auditory evoked potentials, and magnetic resonance imaging of the brain did not show more abnormal findings in the divers. Four $(10 \%)$ divers had had episodes of cerebral dysfunction during or after the dives; two had had seizures, one had had transitory cerebral ischaemia and one had had transitory global amnesia. It is concluded that deep div-
\end{abstract}

Norwegian Underwater Technology Centre, Bergen K Todnem, B K Kambestad

Department of Neurology, University of Bergen

K Todnem, H Nyland, H Skeidsvoll, J A Aarli

Department of Radiology, Rogaland Central Hospital, Stavanger

R Svihus

Department of Medical Technology, SINTEF, Trondheim and MR Centre, Medical Section, University of Trondheim

P Rinck

Section for Medical Informatics and Statistics, University of Bergen, Norway

T Riise ing may have a long term effect on the nervous system of the divers.

Diving to below 180 metres of seawater (msw) has been performed both as simulated onshore divesfor example, the Sagittaire and Atlantis series ${ }^{1}$-and as open sea dives. It has been concluded that divers can be safely compressed to depths as great as 686 metres of seawater $(\mathrm{msw})^{2}{ }^{2}$ Since 1980 eight simulated deep dives from 350 to $500 \mathrm{msw}$, corresponding to ambient pressures of 3.6 to $5.1 \mathrm{MPa}$, have been performed at the Norwegian Underwater Technology Centre.

The increased hyperbaric pressure influences the nervous system during deep dives. The divers may experience hand tremor, postural instability, gastrointestinal problems, somnolence, and cognitive dysfunction. The neurological symptoms and signs that may occur have been termed the high pressure neurological syndrome (HPNS). This syndrome has been known for more than twenty years. ${ }^{3-6}$

The sea bed of the Norwegian continental shelf with oil and gas resources is situated between 70 and $400 \mathrm{msw}$. Despite progress in robot technology the work of human divers is still required on underwater installations at these depths.

We have previously studied the immediate neurological effects of deep diving. ${ }^{78}$ This report appears to be the first follow up study of deep divers to evaluate possible long term consequences of deep diving. The investigation was part of the National research programme on long term health effects of diving.

\section{Materials and methods}

DIVERS AND DIVES

Forty male divers, mean age 34.9 (range 24-49) years, were examined one to seven years after their last deep dive. These subjects comprised all Norwegian deep divers reported to us at the time except for one who did not want to participate. The deep divers were part of a cross sectional study of 156 commercial divers. ${ }^{9}$ The divers were examined at least two weeks after their last dive.

Deep diving was defined as diving below $180 \mathrm{msw}$. Twenty five divers had participated in one deep dive, 
Table 1 The deepest dive made by the divers

\begin{tabular}{ll}
\hline No of divers & Diving depths (msw) \\
\hline 2 & 190 \\
5 & 200 \\
7 & 300 \\
4 & 350 \\
13 & 360 \\
6 & 450 \\
3 & 500 \\
\hline
\end{tabular}

msw $=$ Metres of seawater.

eight in two, three in three, and four in four deep dives. The dives comprised mostly simulated dives in a hyperbaric facility. The rest were sea dives. Table 1 shows the greatest depths reached by each diver.

\section{EXPOSURE TO DIVING AND EXPOSURE INDICES}

One diver had participated in one simulated dive only, but had never worked as a diver. The others had been commercial divers from one to 23 years (mean 11 years). Mean duration of air diving was 583 (range 45-2331) days, and mean time in saturation was 378 (range 14-706) days. Thirteen of the 40 divers (33\%) had stopped diving at the time of the examination. Four had lost their divers' licence because of neurological problems, and nine wanted a new job. Twenty seven still worked as divers.

Exposure indices (total number of days) for air diving and saturation diving were calculated for each diver. Exposure indices for deep diving were calculated from days in saturation and the greatest depth reached. Total diving was calculated from the sum of the described indices. As the exposure was lognormally distributed, logarithmic transformation was used in the risk factor analysis.

\section{CONTROLS}

The control group consisted of 100 men, mean age 34.0 (range 22-48) years. The inclusion criteria for the control subjects were age between 20 and 50 , no experience of diving, and health standards comparable with requirements for a diving certificate. The control group consisted of offshore personnel and police officers. Some 170 offshore workers were invited to participate by advertising. Fifty three responded and were examined. The rest of the control group was recruited from advertising among 270 policemen. The first 50 responders were examined. Informed consent was obtained from all participants. All expenses were refunded but no salary was paid.

\section{EDUCATION}

Eleven divers $(28 \%)$ had had a formal education of nine years, $20(50 \%) 12$ years and nine $(23 \%)$ more than 12 years. In the control group four $(4 \%)$ had had a formal education of nine years, $52(52 \%) 12$ years and $44(44 \%)$ more than 12 years. Statistical analysis showed that the controls had had more years of formal education than the divers $(p=0.0001$, Pearson $\chi^{2}$ test).

\section{SMOKING HABITS}

Twenty three per cent of the divers and $39 \%$ of the controls smoked cigarettes ( $p=0 \cdot 1$, Pearson $\chi^{2}$ test). The difference between the two groups was not statistically significant.

\section{USE OF ALCOHOL}

This was graded from 1 (low) to 4 (high) in a combined measure of how frequently the subjects drank alcohol and the amount. When the divers were grouped according to use of alcohol, the mean figures (\%; controls in parentheses) were: grade 1: $12(22)$; grade 2: 20 (35); grade 3: 45 (35); grade 4: 23 (8). The divers drank significantly more alcohol than the controls $\left(\mathrm{p}=0.028\right.$, Pearson $\chi^{2}$ test).

\section{INTERVIEW}

A standardised interview was carried out by one neurologist, focusing upon education, previous diseases, and a full diving history including complications possibly associated with diving. Subjects were also interviewed about symptoms from the central (CNS), the peripheral (PNS), and the autonomic (ANS) nervous system, and their use of tobacco and alcohol.

Fatigue, mood lability, irritability, concentration difficulties, recent and long term memory problems, work management problems, headache, and dizziness were defined as CNS symptoms. Problems of short term memory were defined as inability to remember appointments, problems with control of personal belongings, and extensive use of memory aids. Long term problems of memory were defined as poor memory for written material and earlier events. The questions were answered with "no" or "yes", and graded according to the number of positive answers. In cases of "yes" the subjects' own opinion was that they had a real problem, or that the relevant function had decreased significantly over the past five years. Results of neuropsychological testing are not included in this presentation, but have been published previously. ${ }^{10}$

Paraesthesia and pain in feet and hands and muscular weakness were considered as PNS symptoms.

Symptoms from the ANS were defined as cardiac palpitation, excessive sweating, chest oppression, sexual dysfunction, orthostatic hypotension, and episodes of diarrhoea and constipation. In each subject these symptoms may have had causes not originating in the ANS. This was controlled for by further questions. If other relevant causes were found, the symptoms were not attributed to the 
ANS. Symptoms from the PNS and the ANS were graded from 1 ("I never have this symptom") to 4 ("I have this symptom every day").

We calculated a score for neurological symptoms in each subject. The score ranged from 0 in the subject without symptoms to 100 in the subject with symptoms in all variables. The individual scores were transformed to a mean score for divers and controls.

\section{EXAMINATIONS}

A standard neurological examination was performed by one neurologist according to a previously defined protocol. ${ }^{11}$ The findings were classified as either normal or abnormal. Muscle stretch reflexes were graded as symmetric, asymmetric, or increased. Abdominal muscle reflexes were graded as normal, asymmetric, or absent. Plantar reflexes were graded as symmetric, asymmetric, or inverted (Babinski positive). The same scoring system was used as for symptoms. The score ranged from 0 in the subject with no abnormal neurological findings to 100 in the subject with abnormal findings in all variables. The individual scores were transformed to a mean score for divers and controls.

Visual evoked potentials (VEPs) were examined with checkerboard reversal stimulation using a Disa Neuromatic $2000 \mathrm{C}$ and a monitor subtending a visual field size of $11^{\circ} \times 8.8^{\circ}$ and check size of $1^{\circ}$. Luminance and contrast were held constant. Two hundred signals were averaged and N75, P100, and N145 latencies were analysed.

Brain stem auditory evoked potentials (BAEPs) were tested with the same machine. Rarefaction clicks $60 \mathrm{~dB}$ above click hearing threshold were used and the contralateral ear was masked with white noise at $50 \mathrm{~dB}$. Click stimulation was $10 \mathrm{~Hz}$ and 2000 epochs were averaged. Each ear was tested twice and I-V, I-III, and III-V latencies were analysed.

The electroencephalograms (EEGs) were 16 or 21 channel recordings from a Siemens-Elema Minograph. Electrode placement was according to the 1020 system. All EEGs were recorded at the same neurophysiological laboratory and read independently by two neurophysiologists. If they disagreed on an EEG, it was not accepted as abnormal.

Magnetic resonance imaging (MRI) of the brain and brainstem was performed in 25 divers using a Philips Gyroscan S5 operating at a field strength of 0.5 tesla, and with the following protocol: MRI slice thickness $7 \mathrm{~mm}$, field of view $250 \mathrm{~mm}$, and acquisition time $100 \%$. T1 weighted transverse images used a repetition time (TR) of $1500 \mathrm{~ms}$ and echo delay time (TE) of $30 \mathrm{~ms}$. T2 weighted transverse images used a TR of $1500 \mathrm{~ms}$ and a TE of $50 / 100 \mathrm{~ms}$. Ten divers were examined with the same protocol and in the same machine, which was then expanded to a magnetic field strength of 1.5 tesla.
Eighteen controls were examined in the 1.5 tesla machine and with a slightly different protocol. Images were evaluated by at least two readers. If the readers disagreed on a high signal intensity change, it was not accepted as abnormal.

\section{STATISTICAL METHODS}

The Pearson $\chi^{2}$ test and Fisher's exact two tailed test were adopted for comparisons between groups of categorical variables. Student's $t$ test was applied for comparison of continuous variables with approximately normal distribution. Multiple linear regression analysis (neurological symptoms and findings, VEP, BAEP, MRI) and logistic regression analysis (EEG) were used to evaluate the relation between risk factors and the different test results. A stepwise procedure eliminated the covariation between risk factors. The significance of each risk factor in the linear regression was calculated by Fisher's test. For the logistic regression the significance was tested by a $\chi^{2}$ statistic. The stepwise procedure at each step included the risk factor with the highest partial correlation if its $\mathrm{F}$ or $\chi^{2}$ statistic was significant. ${ }^{12}$

\section{ETHICAL CONSIDERATIONS}

Permission to establish a register for deep divers and controls was given by The Data Inspectorate. All subjects were informed that their medical data would be available to themselves in the future, and would be kept in special files in the hospital. The data would be used for scientific purpose only. If otherwise, they would be asked.

\section{Results}

All results refer to one set of data and do not include repetitive examinations.

\section{MEDICAL HISTORY}

Table 2 presents the medical history one to seven years after the deep dives, together with tests of

Table 2 Medical history in divers and controls

\begin{tabular}{lcll}
\hline & $\begin{array}{l}\text { Divers } \\
(n=40) \\
N o(\%)\end{array}$ & $\begin{array}{l}\text { Controls } \\
(n=100) \\
N o(\%)\end{array}$ & $\begin{array}{l}\text { Group } \\
\text { differences } \\
p \text { Value }\end{array}$ \\
\hline $\begin{array}{l}\text { Episodes of cerebral } \\
\text { dysfunction } \dagger\end{array}$ & $4(10)$ & $0(0)$ & $0.006^{\star}$ \\
$\begin{array}{l}\text { Cerebral concussion } \\
\text { Viral meningitis }\end{array}$ & $16(40)$ & $33(33)$ & 0.44 \\
$\begin{array}{l}\text { Other viral diseases } \ddagger \\
\text { Lumboischialgia }\end{array}$ & $26(0)$ & $1(1)$ & 1.00 \\
& $16(40)$ & $42(42)$ & $0.02^{\star}$ \\
\hline
\end{tabular}

^Significant differences between the groups, Fisher's exact two tailed test.

†Episodes compatible with transitory cerebral ischaemia, seizures, and transitory global amnesia; all occurred during or after the deep dives.

†Once or more a year. 
differences between the two groups. Viral infections, defined as episodes with fever and common cold symptoms, occurred significantly more often in the divers than in the controls. No group differences in allergy and pulmonary diseases, gastrointestinal diseases, hypertension, cancer, or mental disorders were found. No one had a history of birth injury, cerebral haemorrhage, diabetes mellitus, angina pectoris, or myocardial infarction.

Table 3 shows the divers' complications in connection with diving. The figures refer to total numbers of complications one to seven years after the deep dives, and not before the deep dives. Fourteen (35\%) of the divers had experienced decompression sickness 2 (DCS 2), and $26(65 \%)$ had experienced DCS 1 or 2 , or both. Decompression sickness 1 was defined as musculoskeletal pain, and DCS 2 as neurological symptoms occurring in or after decompression from a dive.

Four divers (none of the controls) had experienced episodes of cerebral dysfunction during or after their deep dives.

Diver 1 had allergies (strawberries, acetylsalicylic acid). He had had anaphylactic reactions to insect bites twice as a child. During the bottom phase in a dive to $450 \mathrm{msw}$ he developed a severe episodic itching all over his body without focal localisation. No visible skin reaction occurred. On the second day of decompression ( $418 \mathrm{msw}$ ), when sitting writing, he suddenly felt an unpleasant itching localised on his head combined with rotating vertigo, severe nausea, and bilateral myoclonic jerks in the arms. He then became unconscious for about 30 seconds and fell from his chair. On awakening, he had tunnel vision, complete hearing loss, and a feeling that he could not breathe. All symptoms disappeared in five minutes without amnesia. Four hours later, while lying in his bed, he again experienced sudden severe nausea and dizziness, but remained conscious. For the rest of the dive he suffered from gradually decreasing skin itching, almost resistant to medical treatment. None of the other divers had similar symptoms. The oxygen content of the breathing gas during bottom time was 0.4 bar and during decompression 0.5 bar.

Table 3 Complications related to diving in 40 deep divers

\begin{tabular}{lcccc}
\hline & \multicolumn{4}{c}{ Number of episodes for each diver } \\
\cline { 2 - 5 } Complication & 1 & $2-5$ & $>5$ & Total (\%) \\
\hline DCS 2; brain symptoms & 8 & 1 & & $9(23)$ \\
$\begin{array}{l}\text { DCS 2; spinal cord } \\
\text { symptoms }\end{array}$ & 2 & 2 & 1 & $5(13)$ \\
$\begin{array}{l}\text { DCS 1 + 2 } \\
\text { Unconsciousness; }\end{array} \quad 11$ & 13 & 2 & $26(65)$ \\
$\quad$ Not DCS & 7 & 1 & & $8(20)$ \\
Skin bends & 3 & 4 & 6 & $13(33)$ \\
Lung complications & 2 & 2 & & $4(10)$ \\
\hline
\end{tabular}

DCS $=$ Decompression sickness.
Neurological findings and EEG immediately after the dive were unchanged. Electronystagmography disclosed a nystagmus to the right that was not present before the dive; EEG four weeks after the dive showed short episodes with slow wave $(5-7 \mathrm{~Hz})$ activity in the left temporal region.

One year later he experienced a similar episode without obvious provocation. When talking he suddenly noticed itching, which spread from his head to his chest and both arms; he felt unable to think, and had moderate vertigo and blurred vision. He lay down, and developed myoclonic jerks in the chest muscles and slight breathing difficulties. These symptoms lasted for 30 minutes, but his head and arms felt numb for another 10 hours. Treatment with antihistamines had no effect. A neurological examination showed no new findings. An EEG contained slow wave $(5-7 \mathrm{~Hz})$ activity and sharp potentials in both frontal and temporal regions but no definite epileptiform pattern. A brain scan by MRI one year later was normal. He has had no further episodes.

Diver 2 had a mild cerebral concussion when he was five years old. He had had a hypoxic incident during diving with five minutes of unconsciousness 14 years before a deep dive to $360 \mathrm{msw}$. No clinical abnormalities were discovered after this dive. One EEG had been normal before the deep dive. An EEG immediately after the deep dive contained episodes lasting 3-30 seconds with rhythmic theta $(4-5 \mathrm{~Hz})$ activity and sharp potentials in the right temporal region as previously described (diver $8^{8}$ ). The EEG continued to be abnormal with episodic slow activity in the right temporal region. Six months after the dive he had two nocturnal episodes of focal left sided jerks lasting a few seconds. Two years after the dive he had several nocturnal episodes with an unpleasant feeling in his head spreading all over his body, followed by severe asymmetrical jerks in his arms and legs. The subsequent neurological examination was normal and MRI brain scan showed no abnormalities. The episodes were diagnosed as simple partial epileptic seizures.

Diver 3 participated in a dive to $500 \mathrm{msw}$, and then had DCS with musculoskeletal pain. Mild diffuse slow activity (4-6 Hz) occurred in his EEG after the dive (normal before). His EEG was not investigated further at this time.

Four years after the dive he collided with a parked bus when cycling. He was briefly unconscious, had a fracture of the dens epistropheus, and compression fractures of the sixth and seventh cervical vertebra. $\mathrm{He}$ had amnesia for the event and dysaesthesia in both hands, but no other abnormal findings.

Six years after the dive when he was working as a supervisor on a diving ship, he had an 18 hour episode with severely impaired short term memory. When admitted to hospital two days later, he had mild ataxia and nystagmus. Neurological examina- 
Table 4 Neurological symptoms

\begin{tabular}{lrrl}
\hline & \multicolumn{2}{l}{ Mean score $(\%(S D))$} & \\
\cline { 2 - 4 } Symptoms & Divers & Controls & p Value \\
\hline CNS & $11 \cdot 1(16 \cdot 5)$ & $4 \cdot 3(7 \cdot 4)$ & $0.001^{\star}$ \\
PNS & $6.7(11 \cdot 3)$ & $2.0(5 \cdot 7)$ & $0.002^{\star}$ \\
ANS & $8 \cdot 1(6 \cdot 8)$ & $5 \cdot 7(5 \cdot 6)$ & $0.038^{\star}$ \\
\hline
\end{tabular}

*Significant differences between the groups, Student's $t$ test.

tion five days later was normal. An EEG showed diffuse slow wave activity. No abnormal findings were seen on MRI brain scan.

Diver 4 had had a head injury with skull fracture and three days of unconsciousness two years before two dives to $210 \mathrm{msw}$. There were no residual findings. Six years after the dives he had two episodes with generalised tonic clonic seizures. His neurological examination, EEG, and MRI brain scan were normal.

\section{PRESENT SYMPTOMS}

Table 4 shows the present symptoms from the CNS, PNS, and ANS ascertained from the interviews.

The divers had significantly more symptoms than the controls. The most prominent CNS symptom was concentration difficulty (mean score in divers 25 , mean score in controls 4 ( $p=0.0006$, Fisher's exact test)). The most prominent PNS symptom was paraesthesia in the feet and hands (mean score in divers 12 , mean score in controls $4(p=0.008$, Fisher's exact test)). There was no single prominent ANS symptom.

\section{ABNORMAL NEUROLOGICAL FINDINGS}

Table 5 shows the abnormal neurological findings. The divers had significantly more abnormal findings from the motor system, sensory system, and stretch reflexes than the controls. The most prominent abnormal findings were from the sensory system, with reduced sensitivity to cotton wool in the left lower leg (mean score in divers 8 , mean score in controls $0(p=0.02$, Fisher's exact test)). Reduced sensitivity to pin pricks in the left lower leg also occurred significantly more often in the divers (mean score in divers 10, mean score in controls 1 $(p=0.02$, Fisher's exact test $))$. No single finding from the motor system or stretch reflexes prevailed significantly.

Four divers $(10 \%)$ and one control $(1 \%)$ had sensory/motor disturbances compatible with dysfunction of the lumbar spinal cord or roots. One diver's findings were moderate, the others were mild. Two divers $(5 \%)$ and one control $(1 \%)$ had sensory/ motor findings compatible with mild peripheral polyneuropathy.
Table 5 Abnormal neurological findings

\begin{tabular}{llll}
\hline \multirow{2}{*}{$\begin{array}{l}\text { Site of } \\
\text { abnormal findings }\end{array}$} & \multicolumn{2}{l}{ Mean score $(\%(S D))$} & Divers \\
\cline { 2 - 4 } & $0.9(2.4)$ & $0.4(2.5)$ & 0.31 \\
\hline Cranial nerves & $0.2(3.0)$ & $1.2(1.8)$ & $0.01^{\star}$ \\
Motor system & $4.2(13.3)$ & $0.8(3.4)$ & $0.02^{\star}$ \\
Sensory system & $1.2(2.4)$ & $0.4(1.3)$ & $0.01^{\star}$ \\
Stretch reflexes & $5.0(19.0)$ & $1.5(11.1)$ & 0.18 \\
Plantar reflexes & $8.8(22.3)$ & $7.0(23.6)$ & 0.69 \\
Abdominal reflexes & 8.09 & \\
\hline
\end{tabular}

^Significant differences between the groups, Student's $t$ test.

\section{RISK FACTOR ANALYSIS}

The possible causes for neurological symptoms and signs in this study were considered to be age, use of alcohol, a history of cerebral concussion and lumboischialgia, previous episodes of DCS 2, total number of episodes of DCS 1 or 2 , or both (DCS $1+2$ ), exposure to air and saturation diving, and exposure to deep diving. Individual subject scores were used for neurological symptoms and findings by neurological examination. In these analyses step zero presents the partial correlation of each risk factor on the tested variable. In further steps the factor with the highest partial correlation appears. Some of the risk factors could be internally associated (for instance, divers with long exposure to saturation diving may also have performed more air diving and deep diving). Only factors with independent effects occur in further steps.

Table 6 presents the risk factor analysis for neurological symptoms and signs. Significantly correlated with neurological symptoms were previous episodes of DCS 2, exposure to saturation diving, total diving, deep diving, and air diving, DCS $1+2$, previous cerebral concussion, and lumboischialgia. Saturation diving, cerebral concussion, lumboischialgia, and DCS 2 were independently significant.

Significantly correlated with abnormal findings in the neurological examination were exposure to air diving, total diving, saturation diving, and deep diving, DCS $1+2$, DCS 2 , and age. Air diving and age were independently significant.

\section{ELECTROENCEPHALOGRAPHY}

Seven $(18 \%)$ of the divers and five $(5 \%)$ of the controls had an abnormal EEG ( $p=0.039$, Student's $t$ test). The EEG changes consisted of focal or diffuse slow wave activity and sharp potentials. (Twenty eight of the divers had had a normal EEG before the deep dives. The other 12 had not been examined. The previous results are not included in this study.)

Three of the four divers with episodes of cerebral dysfunction had an abnormal EEG. An abnormal 
Table 6 Risk factor analysis for neurological symptoms and signs in divers and controls. Stepwise linear regression analysis is used. Step zero shows the univariate relations $(R=$ partial correlation) between findings and the risk factors. The last step shows the independent correlations found

\begin{tabular}{|c|c|c|c|c|}
\hline & \multicolumn{2}{|c|}{ Step zero } & \multicolumn{2}{|c|}{ Last step } \\
\hline & $R$ & p Value & $R$ & p Value \\
\hline $\begin{array}{l}\text { Neurological symptoms (NSY): } \\
\text { DCS } 2 \\
\text { Saturation diving (ln) } \\
\text { Total diving (ln) } \\
\text { Deep diving (ln) } \\
\text { Air diving (ln) } \\
\text { DCS } 1+2 \\
\text { Cerebral concussion } \\
\text { Lumboischialgia } \\
\text { Age } \\
\text { Alcohol } \\
\text { NSY }=-0.19+0.044 \text { DCS } 2\end{array}$ & $\begin{array}{c}0.460 \\
0.370 \\
0.351 \\
0.347 \\
0.344 \\
0.299 \\
0.202 \\
0.171 \\
0.164 \\
-0.029 \\
\text { (saturatio }\end{array}$ & $\begin{array}{l}<0.0005 \\
<0.0005 \\
<0.0005 \\
<0.0005 \\
<0.0005 \\
<0.0005 \\
=0.0189 \\
=0.0457 \\
=0.0551 \\
\text { NS }\end{array}$ & $\begin{array}{l}0.172 \\
0.190\end{array}$ & $\begin{array}{l}=0.0455 \\
=0.0256\end{array}$ \\
\hline $\begin{array}{l}\text { Neurological examination (NE): } \\
\text { Air diving (ln) } \\
\text { Total diving (ln) } \\
\text { Saturation diving (ln) } \\
\text { DCS } 1+2 \\
\text { Deep diving (ln) } \\
\text { DCS } 2 \\
\text { Age } \\
\text { Lumboischialgia } \\
\text { Alcohol } \\
\text { Cerebral concussion } \\
\text { NE }=-0.0181+0.0039 \ln \text { (air C }\end{array}$ & $\begin{array}{l}0.360 \\
0.347 \\
0.342 \\
0.337 \\
0.324 \\
0.293 \\
0.220 \\
0.099 \\
0.026 \\
0.017 \\
01 \text { age }\end{array}$ & $\begin{array}{l}<0.0005 \\
<0.0005 \\
<0.0005 \\
<0.0005 \\
<0.0005 \\
<0.0005 \\
=0.0094 \\
\text { NS } \\
\text { NS } \\
\text { NS }\end{array}$ & $0 \cdot 360$ & $=0.0250$ \\
\hline
\end{tabular}

NSY = Symptoms from CNS, PNS, and ANS; NS = non-significant correlation, $p$ value $>0 \cdot 1$.

EEG was also found in four of the other 36 divers. The divers with episodes of cerebral dysfunction had significantly more abnormal EEGs than the others $\left(\mathrm{p}=0.001\right.$, Pearson $\chi^{2}$ test $)$.

Tables 7 and 8 present the risk factor analysis for abnormal EEGs. In this analysis the subjects with abnormal EEGs are compared with the subjects with normal EEGs and correlated with the risk factors. Saturation diving, deep diving, and total diving were significantly correlated with abnormal EEGs, with saturation diving as the independent variable.

VISUAL EVOKED POTENTIALS

These showed a mean N75 latency of $70 \mathrm{~ms}$ in the divers and 71 in the controls $(p=0.5$, Student's $t$ test), a mean P100 latency of $97 \mathrm{~ms}$ in the divers and 98 in the controls $(p=0.5)$, and a mean N145 latency of $137 \mathrm{~ms}$ in both divers and controls $(p=0.9)$. No significant differences were found between the groups.

In the risk factor analysis the combined left and right P100 latencies were significantly correlated with age $(R=-0.226, p=0.0063$, VEP $=$ $108.37-0.312$ age), but not to the other risk factors. In the age group 20 to 46 years latencies decreased with age.

\section{BRAINSTEM AUDITORY EVOKED POTENTIALS}

These showed a mean I-V latency of $4.1 \mathrm{~ms}$ in the divers and 4.2 in the controls $(p=0.6$, Student's $t$

Table 7 Risk factor analysis for abnormal EEGs in divers and controls. Logistic regression analysis is used. Step zero shows the univariate relations between abnormal EEGs and the risk factors. The last step shows the independent correlations found

\begin{tabular}{|c|c|c|c|c|}
\hline \multirow[b]{2}{*}{ Risk factors } & \multicolumn{2}{|c|}{ Step zero } & \multicolumn{2}{|c|}{ Last step } \\
\hline & $\chi^{2}$ & p Value & $\chi^{2}$ & p Value \\
\hline $\begin{array}{l}\text { Saturation diving }(\ln ) \\
\text { Deep diving }(\ln ) \\
\text { Total diving }(\ln ) \\
\text { Air diving }(\ln ) \\
\text { Cerebral concussion } \\
\text { DCS 1 + 2 } \\
\text { Alcohol } \\
\text { DCS 2 } \\
\text { Age }\end{array}$ & $\begin{array}{l}5 \cdot 13 \\
4 \cdot 84 \\
4 \cdot 64 \\
3 \cdot 21 \\
2 \cdot 98 \\
1 \cdot 70 \\
1.58 \\
1.28 \\
0.97\end{array}$ & $\begin{array}{l}0.0235 \\
0.0278 \\
0.0312 \\
0.0733 \\
0.0845 \\
\text { NS } \\
\text { NS } \\
\text { NS } \\
\text { NS }\end{array}$ & $5 \cdot 13$ & 0.0235 \\
\hline
\end{tabular}

DCS $=$ Decompression sickness.

NS $=$ Non-significant correlation, $p$ value $>0 \cdot 1$. 
Table 8 Relative risk for abnormal EEGs

\begin{tabular}{|c|c|}
\hline $\begin{array}{l}\text { Amount of } \\
\text { saturation diving }\end{array}$ & $\begin{array}{l}\text { Relative risk } \\
(95 \% \mathrm{CI})\end{array}$ \\
\hline $\begin{array}{ll}\text { Saturation diving (ln) } & X \\
& X+2 \\
& X+4 \\
& X+6\end{array}$ & $\begin{array}{l}1 \\
1.61(1.03-2.44) \\
2.58(1.06-5.94) \\
4.15(1.09-14.48)\end{array}$ \\
\hline
\end{tabular}

$\mathrm{X}=$ Logarithmic transformation of an occasionally chosen amount of days in saturation.

test), a mean I-III latency of $2 \cdot 2 \mathrm{~ms}$ in both divers and controls $(p=0.2)$, and a mean III-V latency of $1.9 \mathrm{~ms}$ in the divers and 1.7 in the controls $(\mathrm{p}=0 \cdot 1)$. No significant differences were found between the groups. In the risk factor analysis BAEP (combined measure of left and right I-V latencies) was not significantly correlated with any of the risk factors.

MAGNETIC RESONANCE IMAGING OF THE BRAIN AND BRAIN STEM

This was performed in 37 divers and 49 controls. Seven $(19 \%)$ of the divers and $21(43 \%)$ of the controls had high signal intensity changes. The controls had significantly more high signal intensity changes $\left(p=0.045\right.$, Pearson $\chi^{2}$ test). (Twelve of the divers had had a MRI without high signal intensity changes and nine had had a normal computed tomography (CT) of the brain before the deep dives. The others had not been examined. No previous results are included in this study.) The four divers who had lost their divers' licence because of neurological disturbances all had a normal MRI.

In the risk factor analysis the number of high signal intensity changes was significantly correlated with increase in age $(R=0.261, p=0.017)$. The divers with the longest saturation diving exposure had the fewest MRI changes $(R=-0.273, p=0.010)$. No significant correlation with the prevalence of DCS or any of the other factors was found.

\section{Discussion}

Four $(10 \%)$ of the divers had lost their divers' licence because of neurological disturbances, but were still fully employed. One to seven years after the deep dives, however, they had significantly more symptoms from the nervous system than the controls. They also had more abnormal findings by neurological examination and more abnormal EEGs than the controls, but the evoked potentials and the MRI brain scans had no more abnormalities than the control group. It is necessary to take into consideration the facts that $27(68 \%)$ of the divers had had at least one neurological examination and EEG, and many had also had MRI or CT of the brain before the deep dives. They had been partly selected for deep diving on the basis of the medical data. Accordingly, they should be considered the most healthy divers before the deep dives.

The controls were invited by advertising to participate. Neurological examination of a normal population has disclosed minor sensory and motor disturbances, slight ataxic signs, and disturbed reflexes. ${ }^{11}$ Such findings occur more often in older people with a definite increase in men from age 35 . Accordingly it was necessary in this study to include a control group comparable with the divers. The control group does not necessarily represent an average of the invited groups in all respects. For instance, the controls had more years of formal education than the divers. Many policemen have a college education before the police academy. College education is not mandatory for divers, and they are mostly qualified by professional courses or in the navy. The average intellectual level of the divers was slightly above what is found in a normal population. ${ }^{10}$ The divers drank significantly more alcohol than the controls, but the factor analysis showed that alcohol consumption was not a major pathogenetic factor in these cases, probably because none of the divers were alcohol abusers.

The divers reported significantly more symptoms from the nervous system than the controls. Concentration difficulties and paraesthesia were the most prominent symptoms. The divers are more informed of neurological symptoms because of their education and training. The symptoms were, however, strongly correlated with DCS 2, saturation diving, deep diving (depth included), air diving, DCS $1+2$, episodes of previous cerebral concussion, and lumboischialgia (table 6, step zero), and consequently could not be attributed to the different knowledge between the two groups. The exposure indices appear to be internally related, and DCS 2 and saturation diving only were independently correlated to the symptoms in addition to previous cerebral concussion and lumboischialgia. This means that divers who have had DCS 2 have an increased risk of getting more neurological symptoms, and divers with long exposure to saturation diving have an increased risk also in the absence of clinical DCS 2 . The reason may be due to subclinical episodes of DCS, influence of the hyperbaric pressure, or other factors. These results also correspond with findings from neuropsychological examination of deep saturation and air divers. ${ }^{1013}$

One notable finding is the four divers $(10 \%)$ who had experienced episodes of cerebral dysfunction. Diver 1 had his first episode early in the decompression phase from a deep dive. Accordingly, the episode was most probably directly related to the dive, and caused by transitory gas emboli reducing brain stem blood flow. ${ }^{14}{ }^{15}$ It has been shown by in vivo imaging by single photon emission tomography 
that in divers with DCS 2 or cerebral arterial gas embolism, areas of cerebral hypoperfusion may occur and persist up to 14 months. ${ }^{16-18}$ Another possible cause for this episode may have been an adverse effect of the oxygen content, ${ }^{19} 20$ although this is less likely as neurological symptoms rarely occur below 3 bar of oxygen. A vasovagal syncope or an epileptic seizure are other less likely causes.

In diver 2 the seizures occurred at six months and two years after the deep dive. His EEG contained epileptiform patterns shortly after the dive, making the deep dive a probable cause for the seizures. Only one predive EEG was recorded and this was normal. His earlier hypoxic incident may have made his brain more susceptible to injury from the deep dive.

Diver 3 had an episode of transient global amnesia six years after the deep dive. On admission to the hospital he had transient clinical findings of slight ataxia and nystagmus, which are not commonly found in patients with transient global amnesia. ${ }^{21-23}$ This condition has been described in patients from 34 to 92 years of age, but most commonly in the elderly. It is presumably caused by ischaemia of the hippocampus and related structures supplied in particular by the posterior cerebral artery. ${ }^{223}$ As well as the deep dive, his previous head injury could be a contributing factor to this episode. For diver 4, who had experienced two episodes of generalised seizures, his severe head injury is the most plausible cause for the seizures.

The divers had significantly more abnormal findings from the motor and sensory system than the controls. The findings were compatible with dysfunction in the lumbar spinal cord or nerve roots. Neuropathological examinations have disclosed degenerative lesions in the spinal cord both in a case with spinal DCS and in cases with no history of DCS. ${ }^{24}{ }^{25}$ As seen from table 6 these findings show highly significant correlations with air and saturation diving, DCS $1+2$, deep diving (depth included), DCS 2 , and age. The exposure indices in this analysis are also internally related and only air diving and age were independently correlated to the neurological findings. This means that air diving is statistically more strongly correlated than the other exposure indices. The findings were in most cases minor and should by themselves not influence ordinary working capacity. Similar neurological findings have been reported before in air divers. ${ }^{1326}{ }^{27}$ Deep diving was not independently correlated with the symptoms and signs.

Abnormal EEGs were found more often in this group of divers than among the controls despite the fact that most divers $(68 \%)$ had a normal EEG before their deep dive. Exposure to saturation diving and deep diving (depth included) were significantly correlated with the occurrence of abnormal EEGs. We have earlier reported abnormal EEGs in divers immediately after deep diving. ${ }^{8}$ This has also been reported in divers who have never performed deep dives. ${ }^{1328}$ The changes in EEG represent neuronal dysfunction $^{29}$ and may have contributed to the episodes of cerebral dysfunction experienced by some of the divers.

Brain scans by MRI showed significantly more high signal intensity changes in the controls than in the deep divers, and age was independently responsible for the changes in MRI. ${ }^{30}$ The reason for this difference is probably that many of the divers had been selected for deep diving on the basis of having a normal MRI or cerebral CT. High signal intensity changes represent vascular ectasia, dilated perivascular spaces, alteration of myelin, and gliosis. ${ }^{31}$ The significance of these changes is disputed as they are found in both neurologically ill patients and in control subjects. The changes in older subjects correlate with hypertension, diabetes mellitus, hypercholesterolaemia, and cardiac diseases. ${ }^{32}$ In a larger study of saturation divers we found no significant difference in MRI brain scans between divers and controls (unpublished observations). We have previously reported that deep diving to $360 \mathrm{msw}$ gave no immediate changes in MRI brain scans in 18 divers. ${ }^{8}$ The four divers in this study who lost their licence because of neurological disturbances all had MRI brain scans without high signal intensity changes. This supports previous evidence that no major structural changes in the brain occur from deep diving.

One to seven years after the deep dives the divers had more symptoms and signs from the nervous system, and more abnormal EEGs than the controls. Four divers had experienced episodes of cerebral dysfunction during or after the deep dives. The findings had highly significant correlations with deep diving, but they were more strongly correlated with ordinary saturation diving, air diving, and DCS. Most deep divers have performed a lot of ordinary saturation diving and air diving, and this makes the interpretation difficult. This was a cross sectional study of a small subject population, which could be interpreted cautiously. The findings are, however, of medical concern. Special attention should be given to the selection of divers, ${ }^{33}$ and long term follow up programmes should be available for deep divers.

We are indebted to Statoil, Norsk Hydro, and the Royal Norwegian Council for Scientific and Industrial Research who are financing the programme on long term health effects of diving. We are also indebted to Svein Eidsvik MD, Royal Norwegian Navy, Alf Brubakk MD, Department of Biomedical Engineering, University of Trondheim, the participating divers and controls, and the staff of the Norwegian Underwater Technology Centre for help and collaboration in this investigation. 
Requests for reprints to: Kari Todnem, NUTEC, PO Box 6, N-5034 Ytre Laksevåg, Norway.

1 Bennett PB. The high pressure nervous syndrome in man. In: Bennett PB, Elliott DH, eds. The physiology and medicine of diving. London: Bailliere Tindall, 1982:262-96.

2 Bennett PB, McLeod $M$. Probing the limits of human deep diving. Philos Trans $R$ Soc Lond / Biol / 1984;304:105-17.

$\times 3$ Zaltsman GL. Hyperbaric epilepsy and narcosis. Leningrad Sechenov Institute of Evolutionary Physiology and Biochemistry, USSR Academy of Sciences, 1968:1-258.

4 Fructus X, Naquet R, Gosset A, Fructus P, Brauer RW. Le syndrome nerveux des hautes pressions. Marseille Medical 1969;6:509-12.

5 Brauer RW, Dimov S, Fructus X, Fructus P, Gosset A, Naquet $R$. Syndrome neurologique et electrographique des haute pressions. Rev Neurol 1969;121:264-5.

6 Bennett PB, Towse EJ. The high pressure nervous syndrome during a simulated oxygen-helium dive to $1500 \mathrm{ft}$. Electroencephalogr Clin Neurophysiol 1971;31:383-93.

7 Aarli JA, Vaernes R, Brubakk AO, Nyland H, Skeidsvoll H, Tønjum S. Central nervous dysfunction associated with deepsea diving. Acta Neurol Scand 1985;71:2-10.

8 Todnem K, Nyland H, Dick APK, et al. Immediate neurological effects of diving to a depth of 360 metres. Acta Neurol Scand 1989;80:333-40.

9 Todnem K, Nyland H, Kambestad BK, Aarli JA. Influence of occupational diving upon the nervous system: an epidemiological study. $\mathrm{Br} J$ Ind Med 1990;47:708-14.

10 Værnes RJ, Kløve H, Ellertsen B. Neuropsychologic effects of saturation diving. Undersea Biomed Res 1989;16:233-51.

11 Skre H. Neurological signs in a normal population. Acta Neurol Scand 1972;48:575-606.

12 Dixon WJ, Brown MB, Engelman L, et al. BMDP Statistical Software. Berkeley: University of California Press, 1985.

13 Dolmierski R, Kwiatkowski SR, Nitka J, Palubicki J, Laba L. Neurological, psychiatric and psychological examinations of divers in the light of their professional work. Bull Inst Marit Trop Med Gdynia 1981;32:141-52.

14 Toole JF, Cole M. Ischemic cerebrovascular disease. In: Baker AB, Baker LH, eds. Clinical Neurology. Philadelphia: Harper \& Row, 1983;2(15):1-51.

15 Bender MB, Rudolph SH, Stacy CB. The neurology of the visual and oculomotor systems. In: Baker AB, Baker LH, eds. Clinical Neurology. Philadelphia: Harper \& Row, 1983;1(12): 1-132.

16 Macleod MA, Adkisson GH, Fox MJ, Pearson RR. $99 \mathrm{Tc}^{\mathrm{m}}-$
HMPAO single photon emission tomography in the diagnosis of cerebral barotrauma. Br J Radiol 1988;61:1106-9.

17 Adkisson GH, Hodgson M, Smith F, et al. Cerebral perfusion deficits in dysbaric illness. Lancet 1989;8655:119-22.

18 Adkisson GH, Hodgson M, Macleod MA, Sykes JJW, Pearson RR. Cerebral perfusion deficits in dysbaric illnesses: Follow up studies in 18 divers. In: Bitterman $\mathrm{N}$, Lincoln $\mathrm{R}$, eds. Proceedings of the XVth meeting of the European Undersea Biomedical Society. Eilat, Israel, 1989:55-60.

19 Donald KW. Oxygen poisoning in man. Br Med J 1947;1: 667-72, 712-17.

20 Clark JM. Oxygen toxicity. In: Bennett PB, Elliott DH, eds. The physiology and medicine of diving. London: Bailliere Tindall, 1982:200-38

21 Miller Fisher C, Adams RD. Transient global amnesia. Acta Neurol Scand 1964;40:1-83.

22 Shuping JR, Rollinson RD, Toole JF. Transient global amnesia. Ann Neurol 1980;7:281-5.

23 Shuttleworth EC, Wise GR. Transient global amnesia due to arterial embolism. Arch Neurol 1973;29:340-2.

24 Palmer AC, Calder IM, McCallum RI, Mastaglia FL. Spinal cord degeneration in a case of "recovered" spinal decompression sickness. $B r$ Med J 1981;283:888.

25 Palmer AC, Calder IM, Hughes JT. Spinal cord degeneration in divers. Lancet 1987;72:1365-6.

26 Rozsahegyi I. Late consequences of the neurological forms of decompression sickness. Br J Ind Med 1959;16:311-7.

27 Rozsahegyi I, Roth B. Participation of the central nervous system in decompression. Industrial Medicine and Surgery 1966;35:101-10.

28 Kwiatkowski SR. Analysis of the EEG records among divers. Bull Inst Marit Trop Med Gdynia 1979;30:131-5.

29 Martin JH. Cortical neurons, the EEG, and the mechanisms of epilepsy. In: Kandel ER, Schwartz JH, eds. Principles of neural science. Amsterdam: Elsevier, 1985:636-47.

30 Drayer BP. Imaging of the aging brain. Part I. Normal findings. Part II. Pathologic conditions. Radiology 1988;166:785-806.

31 Awad IA, Johnsen PC, Spetzler RF, Hodak JA. Incidental subcortical lesions identified on magnetic resonance imaging in the elderly. Postmortem pathological correlations. Stroke 1986;17:1090-7.

32 Lechner H, Schmidt R, Bertha G, Justich E, Offenbacher H, Schneider $\mathrm{G}$. Nuclear magnetic resonance image white matter lesions and risk factors for stroke in normal individuals. Stroke 1988;19:263-5.

33 Todnem K, Nyland H, Riise T, et al. Analysis of neurologic symptoms in deep diving: Implications for selection of divers. Undersea Biomed Res 1990;17:95-107.

Accepted 1 October 1990 